\title{
A ULTIMA EXPRESSÃO DO PENSAMENTO DE HANS KELSEN $\left(^{\star}\right)$
}

\section{Alaide Taveiros}

Tendo escolhido para tema de nosso trabalho o exame da tese fundamental da Teoria Pura do Direito, afim de apreciá-la em confronto com a última formulação desta, tal como vem compendiada na obra "General Tehory of Law and State" (1) escrita por Kelsen nos Estados Unidos, tomamos para ponto de referência as concepções filosóficas expendidas pelo Prof. Miguel Reale na exposição da sua Teoria tri-dimensional do Direito.

A obra de Hans Kelsen representa o resultado do esforço desempenhado no sentido de apreender o conceito do Direito em sua forma pura, afim de se conseguir obter uma base segura para a construção de uma Teoria do Direito positivc. Para tal adotou KELSEN o método lógico transcendental que, aplicado ao seu objeto, the forneceu os postulados que lhe permitiram proceder a uma “análise da estrutura do direito positivo, a mais exata possível e liberta de qualquer apreciação ético-política de valor." (2).

Quanto ao método, pois, o que desde logo se poderia pretender arguir, é que a aplicação do método lógico transcendental teria, por si só, invalidado todo o esforço de criação de uma teoria que se diz cientifica, como formulação de juizos de realidade com base na observação dos fatos.

Se atentarmos, todavia, para a estrutura do objeto Direito, veremos que tal não se dá.

O Direito, formalmente, aparece como uma NORMA. \footnotetext{
Direito.

*) Trabalho apresentado no Curso de Doutorado, cadeira le Filosofia do

(1) Krisen, Hans, "General Theory of Law and State", trad. inglese Handers Wedberg, Cambridge, Mass., 1949.

(2) Kelsen, "Teoria Pura do Direito, trad. portuguesa de Fernando de Miranda, S. Paulo, 19319 , p. 57.
} 
Aliás, este fato, familiar a todos, é de observação comum a totodos os lugares e todos os tempos.

E o que ressalta Dewey (1) em sua Lógica. como teoria da pesquisa. Diz ele: "O fato de novas propriedades formais revestirem o objeto, em virtude de sua sujeição a certos tipos de operação, nos é familiar em certos campos (arte e Direito), a despeito da própria idéia correspondente a este fato ser pouco familiar à lógica. Por hipotética que possa ser a concepção de que as formas lógicas revestem o material real em virtude do controle exercido sobre as pesquisas afim de que possam estas realizar o seu objetivo, é uma concepção descritiva de algo que existe e pode ser verificado. O desenvolvimento de formas em consequência de operações é um fato estabelecido em certos campos; não é inventado ad hoc em relação às formas lógicas".

E verdade que Dewey se refere "às formas lógicas" apenas e não “às categorias lógico-transcendentais.”

De fato, Kelsen toma como ponto de partida de suas pesquisas a doutrina da norma fundamental, com a qual, segundo suas próprias palavras, "a teoria pura o Direito limita-se a estabelecer as condições lógica-transcendentais do método do conhecimento juríridico positivo usado desde tempos muito antigos, mediante um análise do seu processo real"

E, em sua "Teoria Geral do Estado" (5), fazendo o histórico das suas atividades, que filiou à orientação cientifica surgida na Alemanha, com Von Geriber, Laband e Jellinek, descreve as diretrizes seguidas em seu trabalho teorico, dizendo, quanto ao método adotado, que "estava influenciado, mais ou menos consciente e coerentemente, pela crítica kantiana da razão: dualismo do ser e dever ser; substituicão de hipóstases e postulados metafísicos por categorias transcendentais como condições da experiêncai; transformação de antíteses absolutas (por qualitativas e transistemáticas) em diferenças relativas, quantitativas, intra-sistemáticas; passagem da esfera subjetivista do psicologismo para o âmbito de validez lógico-objetiva."

Pois bem: se por um lado, é possivel alegar estar hoje superada a concepção kantiana de que "os conteudos da percepção e dos conceitos tinham origem em fontes diferentes e, portanto, requeriam uma terceira atividade, a do conhecimento sintético, estabelecendo a sua conexão", não se pode, todavia, deixar de reco-

(3) Dewey, John, "LOGIC, The Theory of Inquiry", New York, 1938, pp. 101. 102 .

(4) Teoria pura do Direito, p. 64.

(5) "Teoria General del Estado", trad. espanhola de Luis Legaz Iacambra, Barcelona, 1934, Prefácio, p. viii. 
nhecer que o racionalismo kantiano teve "uma percepção lógica profunda" da natureza operativa funcional das idéias na apreensão dos dados da experiência quando afirma que isolados os fatos das idéias, "as percepções sãc cegas e os conceitos vazios" (6).

Alem disso, a despeito de se ter operado a fusão do sujeito e objeto, de tal forma que são hoje o objetos possíveis da teoria do conhecimento tanto os objetos reais, os ideais ou ideados, quanto os culturais (valores), não menos verdade é que os fenômenos do mundo real são regidos pela lei da causualidade ao passo que os do mundo do valor, enquanto culturais, são apenas determinados.

A causualidade é uma relação de dependência a-temporal e aespacial; o determinismo é uma relação de dependência temporal, espacial. Os fenômenos do mundo cultural são determinados no sentido de poderem os acontecimentos, produzidos em tempos diferentes, estar ligados por leis de modo tal a ser possivel a previsão de situações desconhecidas (passadas ou futuras), sem que, entretanto, faça sentido o se indagar "porque?" (no sentido causal (7).

Todavia, quando duas cousas em conexão entre si são conreitos. a dependência significa o que os matemáticos expressam pela palavra "função": é uma dependência lógica.

Portanto, o que, antes de mais nada, devemos examinar é se, a despeito do superamento da filosofia informadora do miétodo adotado pela Teoria pura, a doutrina da norma fundamental como idéia funcional, ou esquema lógico de interpretação — terá sido fecunda, possibilitando a apreensão do conceito do Direito na sưa essência ou especificidade.

Vejamos, então, o que ié o juizo hipotético.

Como categoria transcendental, exprime, como todos os juizos da razão que apreende (Verstand), uma relação: contem proposições ou cláusulas em relação recíproca, mas que, em si, não são verdadeiras ou falsas.

Na lógica, concebida como uma teoria da pesquisa, ou seja, assentada sobre a tese fundamental de que "as formas lógicas revestem o objeto quando este é submetido à pesquisa controlada", define-o Dewey como a "posibilidade de um modo de operação expresso sob a forma se-então: Se certos conteudos, então necessariamente certos outros conteudos" E explica: “Tradicionalmente a cláusula se é chamada de antecedente e a cláusula entầo de consequente. Mas a relação é puramente lógica, e os termos

(6) Dewer, ob. cit., p. 111. pp. $5-9$. 
"antecedente" e "consequente" devem ser entendidos em um sentido lógico e não de realidade". E, mais adiante: "Na proposição, "Se um ato de transgressão, então responsabilidade por uma pena", os termos são abstratos e a relação é a-temporal e a-existencial, embora refiram-se os seus conteudos, as idéias de transgressão e penalidade, indiretamente, à realidade (8).

Portanto, a dependência decorrente dessa relação a-temporal e a-existencial, não é causal, mas apenas funcional ou lógica, e isso porque as proposições universais so simplesmente a formulação de operações possiveis, em termos abstratos.

Assim, diz Dewey: "Enquanto as operações não forem executadas, a matéria das proposições é, portanto, abstrata ou a-existencial. Tome-se a proposição "Só se os homens forem livres serão condenados ıcom justiça”. Não se afirma a existência de liberdade nem a de condenação justa. Enquanto é possivel dizer que a existência de homens é postulada, não o é quanto a ser implicada ou expressamente afirmada. A relação afirmada entre liberdade e condenação justa, se de ıqualquer forma válida, será válida ainda mesmo que os seres humanos sejam varridos da existência. Liberdade, justiça e condenação designam caracteres abstratos. Não obstante a proposição formula operações possiveis que, se realmente executadas, são aplicadas à real conduta dos homens de modo a orientar as obsenvações em relação às condições e consequências dos reais casos de condenação. Afora uma tal aplicação, a proposição representa apenas uma posibilidade abstrata dependente da definição de liberdade e justiça que, quanto à existência, pode muito bem ser arbitrária. A proposição pode, pois, ser refutada pelas proposições contrárias "Só se as ações dos homens forem causalmente condicionadas, pode a condenação ser eficaz, e só quando eficaz é justificável. A não ser que ambas as proposições sejam empregadas para orientar as operações humana (com relação às condições e às consequôncias da condenação), nenhuma razão existe para se decidir a favor de uma destas duas possibilidade abstra. tas de preferência à outra" (9).

Portanto, mesmo tendo deixado de ser o juizo hipotético uma categoria transcendental ou um "dever ser", para passar a representar uma simples "possibilidade" de um modo de operação expresso sob a forma "se-então", ainda assim é a forma lógica reves. tida pelo objeto Direito. 
Se assim é, e se, segundo Kelsen, a teoria juridica pura é uma teoria do Direito positivo, claro está que, tomando como esquema de interpretação a norma fundamental, não poderia esta serformulada senão em termos do Direito positivo. E o conceito de "positividade", tal como o estabelece KeLSEN em sua "Teoria Geral do Estado" (10), consiste, apenas, no estabelecimento de "uma relaçâo determinada por um máximo e um mínimo entre o conteudo do Direito (válido como ordem normativa) e o conteudo da correspondente ordem natural do acontecer efetivo (como um setor da natureza)." Lógicamente é o que se consegure mediante a formulaço da proposição contrária refutando a primeira.

Em relação ao método lógico, resta-nos salientar aqui dois pontos importantes: um que diz respeito ao problema da relação entre a proposição universal e a genérica; e outro, relativo ao processo propriamente dito da pesquisa lógica.

Quanto ao primeiro ponto, diz DEWEY: “Uma vez reconhecido que uma proposição universal é a fórmula de uma operação possivel, o principal problema lógico sobre tais proposições diz respeito à sua relaçâo com as proposições genéricas; isto é, à sua relação com a determinação dos traços distintivos que descrevem as espécies. De acordo com o ponto de vista apresentado aqui, a relação é conjugada."

$\mathrm{E}$, em relação ao "processo de pesquisa (lógica) como pesquisa”, diz ainda Dewey: “... consiste em tratar as proposições gerais, que são formulações dos meios de ação como hipóteses um modo de tratamento equivalente a tratar como possiveis, ao envés de exigido ou necessário, os modos de ação formulados. Esta maneira de tratar os conceitos tem o seu impacto direto tambem sobre a formação das espécies. Pois, exige que as bases destas sejam procuradas e as bases devem ser de modo a satisfazer (inclusiva e exclusivamente) os requisitos das hipóteses adotadas e empregadas. Uma vez que a realidade é redlidade, e os fatos sobre a mesma são inflexíveis, os fatos estabelecidos servem para testar a hipótese empregada; de maneira que quando existe reiterada discrepância entre os fatos observados e os requisitos do conceito (hipótese ou teoria), tem-se base material para modificação da hipótese. Existe aqui também um movimento dentro da pesquisa, controlada pelas operações através das quais as situações problemáticas são resolvidas. (12)

(10) ob. cit., p. 24.

(11) ob cit., p. 274

(12) idem, p. 266 
A Teoria pura do direito, partindo da observação de que o fato social havido como jurídico "recebe o seu sentido e a sua sig. nificação propriamente jurídicos em virtude de uma norma que a ele se refere, convertendo-o no seu próprio conteudo; de tal forma que $o$ ato pode ser interpretado em função da norma que lhe atribuiu a qualidade jurídica" (13), serviu-se da norma como "esquema de interpretação."

Dentro, pois, do gênero normativo em que se inclui o Direito vai-se buscar como caracterizar a espécie "juridica".

O dever ser da norma juridica, verifica-se não corresponder ao "dever ser" da norma ética. A norma ética reza: "Não mates" A norma juridica: "Se matares, serás punido." No caso, pois, da norma juridica, o dever ser é apenas a indicação da relação expressa pelo juizo hipotético, isto é, o "enlace" (imputação) do antecedente (fato condicionante) com o consequente (ato condicional). E a indicação de dois deveres: o dever de se abster o indivíduo da ação contrária à conduta desejada; e o DEVER, por parte do orgão estatal competente, de praticar a ação condicionada, ou seja. o ato de coação.

Portanto, se a NORMA indica o gênero próximo, o ato de coaçâo é que dá a diferença específica, e, formulada como um juiz hipotético, o fato condicionante recebe o nome da "anti-juridicidade" e o ato condicionado o de "consequência jurídica" (o ato de coação, a pena).

o direito nada mais é, então, que uma ordem de coaçẩo exterior, ou uma técnica social especifica, ou ainda sistema de normas.

A validade das normas juridicas que fazem parte de um determinado sistema juridico, não dependerá, portanto, do seu conteudo, mas, tão somente, do modo pelo qual tiverem sido estabelecidas. A sua validade decorre da própria estrutura lógica do sistema de normas no qual se integram: "uma pluralidade de normas constitui uma unidade, um sistema, uma ordem, se a sua validade puder ser referida a uma NORMA UNICA como último fundamento dessa validade" (14)

Por conseguinte, o problema da Teoria pura é procurar as bases que possam satisfazer os requisitos da sua hipótese.

(13) Teoria pura do Direito, p. 10.

(14) Teoria pura do Direito, p. 57. 
Vejamos, então, como estabelece KELSEN a maneira pela qual terá sido encontrada esta norma fundamental, base última da validade do sistema.

Na sua “Teoria Pura do Direito", lemos o seguinte: “ Se se pergunta qual a razão porque um ato de coação qualquer, por exemplo, o fato de um homem tirar a liberdade a outro, metendo-o na cadeia, é um ato jurídico, pertencente a determinado sistema de Lireito, a resposta é a seguinte: porque esse ato foi prescrito por uma determinada norma individual, por uma sentença judicial. Se se pergunta ainda porque razão esta norma individual vale como elemento dum determinado sistema juridico, a resposta é: porque foi criada de harmonia com or Código Penal. E se, posteriormente, se pergunta qual o fundamento da validade desse Código Penal, vai-se parar, no fim de tudo, à Constituição do Estado, de acordo com as prescrições da qual foi criado o Código Penal pelos orgãos competentes e segundo o processo estabelecido na mesma constituição. Mas se perguntarem pelo fundamento da validade da cons. tituição, na qual se baseiam todas as leis e todos os atos jurídicos realizados com base nelas, vai-se parar, talvez, a uma constiturição mais antiga e, finalmente, à primeira constituição histórica, outor. gada por algum usurpador ou por algum parlamento constituido por qualquer forma. Ora bem: todo o conhecimento da ordem jurídica baseada nesta constituição, tem de partir de um suposto funddmental, a saber: que aquilo que o primeiro orgão histórico constituinte organizou como expressẩo da sua vontade, tem valor de norma. "Deve realizar-se a coação pela forma e nas condiç,ões determinadas pelo primeiro legislador constituinte ou pelos orgãos em quem ele delegou": é esta a formulação sistemática da norma fundamental de ruma ordem jurídica." .. "Supondo a validade des. sa norma, é tambem VÁLIDA a ordem jurídica que nela se baseia." (15)

No mesmo sentido, em sua "General Theory of Law and State", com omissão da frase, como expressão da sua vontade, conforme se vê da transcrição aqui dada da parte final: “ Ultimately we reach some constitution that is the first historically and that was laid down by an individual usurper or by some kind of assembly. The validity of this first constitution is the last presupposition, the final postulate, upon which the validity of all the norms of our legal order depends. It is postulated that one ought to behave as the individual, or the individuals, who laid down the first consti. tution have ordained."

(15) ob. cit., pp. 62-63.

(16) ob. cit., p. 115. 
Estabeleceu-se, por esta forma, o momento da criação da ordem jurídica, a sua ORIGEM: coincide com o estabelecimento da primeira CONSTITUIÇÃO; tem origem, pois, em um fato histórico.

Não se indaga do PORQUE desse fato. Todavia, busca-se a sua condicionalidade, uma vez que a eficácia da ordem jurídica estatal, assim criada, depende de uma determinada condição, ou seja, da sua aplicação de fato uma vez que a matéria ou conteudo das proposições do juizo hipotético se concretizam no ato da operação.

KELSEN, em sua Teoria pura do Direito, já deixa stumariamente indicado ser a eficácia um principio ảa ondem jurídica internacional, dizendo:

"Se alguem perguntar como é determinado o conteudo da norma fundamental, a resposta que resulta de uma análise severa das opiniões juridicas é a seguinte: "de acordo com o fato que cria aquela ordem à qual corresponde, até certo ponto, a conduta efetiva dos ho. mens a quem essa ordem se destina."

E, logo adiante, esclarece ter com isto ficado determinado apenas o conteudo de uma ORDEM JURIDICA POSITIVA e não estatal, ou seja, a do Direito internacional, $E$ isso porque é o Direito internacional que determina:

"1.0 - que uma ordem coativa diretamente subordinada ao direito internacional é legítima, ou, por outras palavras, que a comunidade constituida por essa ordem é considerada um estado pelo Direito internacional, precisamente naquele território em que, de forma permanente, a ordem exerce uma influência real; $2^{\circ}$ - que aquele GOVERNO que alcançou o poder em consequência de uma revolução ou de um golpe de Estado, tambem deve considerar-se como Governo legítimo em face do Direito internacional, se for capaz de obter uma obdiência durável para as normas por ele estabelecidas. Este princípio é que determina a norma fundamental de uma ordem jurídica estadal."

(17) ob. cit., p. $€ 5$

(18) idem, p. 66 
A despeito de haver declarado que o ESTADO, no sentido do Direito internacional, è aquela ordem estabelecida de forma permanente por um governo que ali exerce influência real, governo esse que se legitima tão somente por esse fato, independentemente dos meios de que tenha lançado mão para se impôr, todavia, conforme se verificará adiante, a partir do momento em que se constituiu a Ordem Jurídica, fica instituido o Principio da Autoridade. Daí por diante a Soberania é do Direito e não mais da FORÇA.

É o que se percebe claramente dos termos em que estabeleceu Kelsen o aparecimento da norma fundamental, na sua "Teoria Geral do Estado":

"Se se indagar da razão pela qual determinado fato concreto, ou determinada ação humana (por exemplo, uma ordem, um contrato, ưm ato de coação) é um ato juridico; da razão pela qual este ato pertence a determinada ordem juridica, à ordem jurídica de determinado Estado, quer dizer, em virtude da qual deve ser explicado como ato dessa ordem jurídica, a resposta consiste em se dizer estar esse fato particular relacionado com uma norma geral da qual representa a concretização constituindo a norma, ao mesmo tempo, uma das proposições jurídicas do sistema em questão.

E se ulteriormente se indagar porque esta norma é uma proposição juridica, e uma proposiçấo jurídica de determinado sistema, chegar-se-á, através de um número maior ou menor de etapas intermédias, a verificar que essa norma - quer dizer, a lei, em sentido técnico $\longrightarrow$ foi estabelecida por uma determinada autoridade; por tal monarca ou tal parlamento, com atribuições para fazê-lo. E se indagarmos ainda da razão pela qual justamente este fato serve de fundamento do caracter jurídico, quer dizer, da circunstância de pertencerem à ordem juridica de determinado Estado quantos fatos estiverem em relação com a mesma, encontramo-nos, partindo do pressuposto básico desta argumentação, ante uma "norma fundamental"; ou, em outros termos: tal norma estabelece como suprema autoridade legislativa o monarca, o parlamento, o povo. Para alem dessa norma fundamental, para aĩem dessa proposição jurídica ordinária, não se pode indagar de fundamento ulterior, em virtude precisamente de seu caracter de "pressuposto". 
É neste pressuposto básico é que se encontram as raizes uo que se cnama Soberania da ordem, juridica estatal, consuculua por tal norma tundamentaı." (1y).

E por isso que KELSEN điz que o "Direito regula a sua própria criação", esclarecendo que "a unidade da ordem juridica consiste em um encadeamento de atos de criação". Todavia, o sistema de normas de Direito, não é um sistema de normas coordenadas, "colocadas ao lado umas das outras, mas uma série escalonada de diferentes zonas normativas, que, em esquema, podemos apresentar da forma seguince: o grau supremo de uma ordem juridica estatal é formado pela constituição_ no sentido material da palavra -, cuja função essencial consiste em determınar os orgãos e o processo de criação das normas jurídicas gerais, quer dizer, da legislação. O grau imediato é constituido pelas normas gerais criadas pelo processo legislativo, cuja função consiste não só em determinar os orgãos e o processo, mas tambem, em essênicia, o conteudo das normas individuais, criadas ordinariamente pelos tribunais e autoridades administrativas. Uma norma geral, que relaciona um fato abstratamente determinado com uma consequência determinada, tambem, em abstrato, necessita de ser individualizada para ter sentido. É preciso verificar se se deu ou não in concreto um fato que a norma geral determinou in abstrato, e para este caso concreto precisa de realizar um ato concreto de coação, isto é, precisa em primeiro lugar determiná-lo e, depois, realizá-lo, aplicando as determinações abstratas da norma geral." (20)

Esta a função do Poder Judicial, função que representa a continuação do processo de criação jurídica do geral para o individual: individualização ou concretização da norma jurídica geral ou abstrata.

É nisto que consiste a justiça. Justiça significa a manutenção de uma ordem positiva pela conscienciosa aplicação da mesma. E a justiça "sob a lei" A declaração de que o comportamento de um indivíd lio é "justo" ou "injusto" no sentido de "legal" ou "ilegal" significa que o comportamento corresponde ou não a uma norma legal pressuposta válida pelo individuo que julga porque esta norma pertence a uma ordem legal positiva. Esta declaração tem logicamente o mesmo caracter de uma proposição na qual um fenômeno concreto está implicito em um conceito abstrato."

(19) ob. cit., pp. 135-136

(20) “Teoria pura do Direito", p. 67

(21) "General Theory of Law and State", p. 14 
O fato da concretização de uma norma, que para Ḱelsen representa um ato de criação do direito, é o que $\in \mathrm{m}$ linguagem comum significa validade $d a$ lei, ou a eficácia do direito, usadas ambas as expressões como sinônimas.

Todavia, o sentido da linguagem comum não corresponde ao sentido técnico em que estas expresões são empregadas na Teoria pura, uma vez que para esta, validade corresponde a um ato de execução do direito ou de criação de uma norma individual, enquanto eficácia correspondente ao momento da criação do direito, ao estabelecimento de uma ordem parcial ou nacional.

Kelsen explana, da seguinte forma, o que seja este principio de eficácia:

"De acordo com este princípio do Direito internacional uma autoridade realmente estabelecida é o governo legítimo, a ordem coercitiva decretada por este governo a oidem jurídica, e a comunidade constituida por esta ordem, um ESTADO no sentido do Direito Internacional, na medida que esta ordem é de uma maneira geral eficaz. Este princípio geral é uma norma positiva do Direito Internacional que, aplicada às circunstâncias concretas de uma ordem jurídica nacional individual, estabelece a norma individual dessa ordem jurídica nacional. Portanto, as normas básicas das diferentes ordens juridicas nacionais blaseiam-se em uma norma geral da ordem juridica internacional." (22)

E estabelece, então, a sua tese:

"Se concebermos o Direito internacional como uma ordem jurídica à qual se subordinam todos os estados (e isto significa todas as ordens juridicas nacionais), então a norma básica da ordem jurídica nacional não é uma mera hipótese da reflexão jurídica, mas uma norma jurídica positiva, uma norma do Direito Internacional aplicada à ordem juridica de um Estado concreto. Admitindo-se o primado do Direito internacional sobre o direito nacional, o problema da norma básica desloca-se da ordem juridica nacional para a ordem juridica internacional. Então, a única norma básica verdadeira, 
norma que não é criada por um processo jurídico, mas pressuposto pela reflexão juridica, é a norma do direito internacional." (23).

E, não sendo o Direito internacional um direito estatal, mas apenas uma ordem jurídica positiva, a norma básica do Direito Internacional deve ser a norma que favorece o costume como um fato gerador de uma norma, e, diz KELSEN, esta pode ser formulada assim: "os estados devem conduzir-se como de costume se tem comportado." (24).

E, embora tenha declarado Kelsen, na sua "General Theory of Law and State", escrita nos Estados Unidos, que o "principio da eficácia pode, entretanto, ser adotado em uma certa extensão tambem pelo direito nacional e, assim, dentro da ordem nacional juridica a validade de uma norma particular pode depender da sua eficácia", como no caso de "poder uma norma jurídica perder a sua validade pelo desuso" (25), isso não significa, de modo algum, uma modificação de ponto de vista em relação à Validade como correspondendo ao ato de execução da norma e, EFICíACIA como ato de criação da ordem jurídica.

Realmente, no parágrafo anterior àquela acima transcrito, declarou KeLSEN explicitamente: "O fato da validade de uma ordem jurídica depender da sua eficácia não implica, conforme já se salientou, que a validade de uma norma particular dependa da sua eficácia. A norma jurídica particular permanece válida enquanto for parte de uma ordem válida. A questão de se saber se uma norma particular é válida é respondida recorrendo-se à primeira constituição. Se válida esta, então todas as normas criadas de uma maneira constitucional são tambem válidas. O princípio da eficácia, corporificado no Direito internacional, refere-se imediatamente apenas à primeira constituição da ordem jurídica nacional e, portanto, a esta ordem apenas como um todo." (26)

Aliás havendo KeLSEN, na obra em questão, apresentando uma reformulação da sua teoria pura com as vistas voltadas para a realidade anglo-saxônica do Direito, era natural que tivesse levado em conta as peculiaridades juridicas de um direito não codifirado, dos "case-law" Não poderia, pois, deixar de analizar a fundo o caso do "desuso", que definiu como "o efeito jurídico negativo do costume" Ora, assim como a norma pode ser criada pelo costume, um costume contrário pode anulá-la. Mas, ainda assim, diz Kelsen,

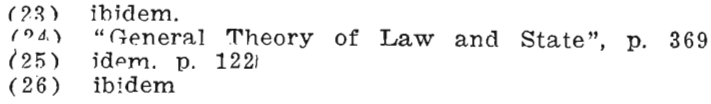


"será un erro identificar a validade com a eficácia da norma; estas continuam sendo dois fenômenos diferentes. A norma anulada pelo desuso foi válida durante um lapso considerável de tempo sem ter sido eficaz. Só uma falta duradoura de eficácia é que põe fim à validade." E conclui: "A relação entre validade e eficácia parece, pois, ser a seguinte: Uma norma é uma norma legal válida se: (a) foi criada segundo o modo aeterminado pela ordem juridica à qual pertence, e (b) se não tiver sido anulada, seja pela forma determinada pela referida ordem jurídica, seja por meio do desuso, seja em virtude do fato de haver a ordem juridica, como um todo, perdido a sua eficácia."

Por conseguinte, de acordo com a tese do primado do direito internacional, defendida por KrLsen, a única norma básica verdadeira, porque fundada no costume e, portanto, apreendida na realidade, é a norma básica do Direito internacional.

Historicamente o Direito internacional surgiu no período subsequente ao declírio do Santo Império Germânico e à cisão da Igreja cristã - ambos impérios esses sob cujo domínio tinham sido reunidos os estados europeus em uma comunidade jurídica superior como resultado da necessidade de se pôr ordem no cáos reinante nas relações recíprocas dos estados nacionais, então nascentes.

A função primária do Direito internacional consiste, assim, em delimitar as esferas de validade espacial-temporal e material-pessoal das ordens jurídicas dos Estados uns em relação aos outros, coordenado-as, ou seja, tornar possível a contvivênicia pacífica da família das nações. Em resumo, a substituição do império da força pela ordem de direito.

\section{III}

Através do princípio da eficácia efetua KELSEN a passagem da esfera normativa abstrata, onde as relações estabelecidas são apenas logicamente necessárias, para a esfera do normativismo real da conduta humana, com o seu conteudo causal e cultural.

O movimento circular da análise procedida pela Teoria pura do Direito foi um movimento dentro da pesquisa "controlada pelas operações através das quais as situações problemáticas são resolvidas."

A solự̧ão dessas situações problemáticas é que, na opinião dos contraditores e criticos da Teoria pura do Direito, importaram no "esvaziamento do conteudo do Direito", de tal modo que KeLSE: o teria reduzido a uma simples norma.

(27) idem, pp. 119-120. 
Confundiram, assim, a hipótese de trabalho adotado por KELSEN, na pesquisa do seu objeto, com o próprio objeto.

De fato, a norma fundamental foi utilizada apenas como "esquema de interpretação" na análise das situações problemáticas a resolver.

E os resultados obtidos provaram a excelência da hipótese adotada, permitindo, assim, à Teoria pura definir o direito como um sistema de normas.

A definição é rigorosamente exata.

Se em termos da lógica aristotélica (sem as deturpações que lhe foram introduzidas na Idade Média), a "definição é a forma que a essência toma quando conhecida", e, neste sentido, "longe de ser verbal, ou mesmo um processo conveniente ou produto do "pensamento", é a garra cognitiva daquilo que define (assinala) a substância ontológica" (28), atualmente o valor da definição reside todo no fato de, conforme diz Dewey, serem instituidos os significados dos conceitos tendo em vista representar possibilidades de solução. E só estarão os conceits em condições de preencher esta tarefa quando redutíveis a caracteres necessariamente inter-relacionados exatamente porque constituem a análise de uma única concepcão. "O valor (validade) de qualquer análise de determinada noşão - sendo esta análise a definiçầo - é finalmente fixado pela capacidade de instituirem os caracteres inter-relacionados uma série de rigorosa substituições no discurso." (29).

$\mathrm{E}$ foi exatamente o que conseguiu a Teoria pura do Direito, com a sua hipótese de trabalho e o método lógico.

Longe, pois, de esvaziar o "conteudo do Direito", tornou possivel o ingresso, nessa província, de todos os valores, ou de todos objetos vetoriais.

A condição única imposta é a de se conter a conduta humana dentro de certos limites - superior e inferior - prefixados.

De fato, diz Kelsen "o conteudo de uma norma básica é determinado pelos fatos, através dos quais uma ordem é criada e aplicada e à qual, em geral, se conforma o comportamento dos indivíduos regidos por essa ordem. Não se exige que o comportamento de fato, dos individuos, esteja em absoluta conformidade com a ordem. Ao contrário, um certo antagonismo entre a ordem normativa e o real comportamento humano, ao qual se referem as normas da ordem, deve ser possivel. Sem uma tal possibilidade, a ordem norreativa perderia completamente o sentido. 0 que acon-

(28) DEWEY. ob cit., p. 86.

(29) idem, p. 343 
tece necessariamente sob as leis da natureza não deve ser prescrito por normas: A norma básica de uma ordem social com a qual o real comportamento dos individuos se conformasse sempre e sem excepça rezaria o seguinte: Os homens devem conduzir-se tal como de fato se conduzem, ou: deves fazer o que realmente fazes. Ta! ordem teria tão pouco sentido quanto uma ordem com a qual o comportamento humano não se conformasse de modo algilm, mar fosse contrariada sempre e a respeito de tudo.” E, conclue:

A relação existente entre a validade e a eficácia de uma ordem jurídica - ou seja, por assim dizer, a TENSÃO entre o "dever ser" e o ser - só pode ser determinada por uma linha fronteiriça superior e inferior. A concordância não deve exceder um certo máximo e não cair abaixo de um certo mínimo."

E o princípio da eficócia que na esfera estatal, ou na ordem jurídica nacional, se traduz no conceito de positividade, desenvolvido por KeLsen na sua "Teoria Geral do Estado" como segue: "Entre o conteudo do dever ser, que é o do sistema "Estado" (quier dizer, da ordem normativa do Estado como ordem jurídica) e o conteudo do ser (que é o sistema da ordem da natureza submetida ao causalismo cego) devem ser possiveis certas antiteses. Uma norma cujo conteudo estivesse de tal modo determinado que o conteudo do ser, do acontecer efetivo, jamais estivesse em contradição com aquela - como a norma deves fazer o que quiseres - teria perdido seu sentido normativo específico." E acrescenta: "A investigaçấo orientada no sentido de averiguar a relaçâo entre o conteudos de ambos os sistemas heterogêneos, tem de limitar-se o marcar um limite superior e um inferior: os conteudos de ambos sistemas não são totalmente coincidentes, nem divergentes de modo absoluto. A tensão não pode ultrapassar um máximo - pois, neste caso perderia todo sentido a hipótese de um sistema de "Di reito" autônomo - mas tambem não pode ir alem de um mínimo, porque, então, desapareceria toda possibilidade de se utilizar o sistema de direito como medida de valoração da conduta real do homem, dos conteudos do sistema natural. Esta relação,. é a que se traduz no conceito de positividade."

Um exemplo apenas, à guisa de ilustração.

Tratando do problema da Soberania do Estado em confronto com o conceito de liberdade da vontade, diz o seguinte: "A hipótese da liberdade tem, antes do mais, o sentido puramente negativc de uma repulsa à determinação pela lei da causualidade, pois, esta

(30) "General Theory of Law and State", p. 120

(31) ob. cit., p. 24 
legalidade é totalmente estranha ao reino do dever ser. Mas, positivamente significa e afirmaçẫo de uma relação de imputação. Todo mundo sabe que a "liberdade" e a "imputação" são cousas correlatas. Pois bem, é preciso inverter os termos da conexão, e em lugar de dizer que a uma pessoa só se pode imputar algo porque e enquainto livre, dever-se-á afirmar que uma pessoa só é livre porque $e$ enquanto algo lhe é imputado; na medida, pois, que constitui um centro de imputação, um ponto último da imputação. Emibora a liberdade da vontade, no sentido de ponto último da imputação, possua um sentido aceitável, inteiramente compativel com a determinação causal da vontade psicológica, antes do mais deve-se advertir que só é possivel admitir uma liberdade absoluta da personalidade individual do ponto de vista de uma teoria ética que veja no indivíduo o mais alto valor, o único "portador" de todas as normas morais. Não temos de discutir aqui se tal ética individualista é possivel e até que ponto.. Perante a ordem jurúdica, a pessoa individual, a pessoa física, só pode aparecer como relativamente livre; não pode constituir senão um centro provisório, não definitivo de imputação, enquanto estiver em relação com a ordem jưrídica: justamente naquela relação de unidade em virtude da qual entra na esfera do conhecimento jurídico e é conhecida como Direito, como crdem jurídica parcial."

A partir, pois, do momento em que o Direito estabeleceu limites à liberdade individual é que esta se transformoü em valor. De fato, só quando unida à responsabilidade é que a liberdade adquire socialmente um sentido.

Eis como o valor se insere na Teoria pura do Direito.

(32) "Teoria Geral do Estado", pp. 99-95 